\title{
An Assessment Framework for PV Parallel MPPT Configuration with a New Utilization for UIPS Loads
}

\author{
MOSTAFA EL-SAYED, AHMED HUZAYYIN, ABDELMOMEN MAHGOUB, \\ ESSAM ABULZAHAB \\ Electrical Power Engineering, \\ Faculty of Engineering, \\ Cairo University, \\ Cairo University Road - Giza, \\ EGYPT
}

\begin{abstract}
The prevalence rate of photovoltaics (PV)-based generation systems has increased by more than 15 folds in the last decade, putting it on the top compared to any other power generation system from the expandability point of view. A portion of this huge expansion serves to energize standalone remote areas. Seeking improvements from different aspects of PV systems has been the focus of many studies. In the track of these improvements, parallel MPPT configuration for PV standalone systems have been introduced in the literature as an alternative to a series configuration to improve the overall efficiency of standalone PV systems. However, this efficiency improvement of the parallel MPPT configuration over the series one is not valid for any standalone application, therefore an assessment procedure is required to determine the most efficient MPPT configuration for different standalone applications. Therefore, in this study, an assessment procedure of parallel MPPT is conducted to demonstrate the suitability of utilizing such a configuration compared to series one, based on load daytime energy contributions. This assessment will help PV system designers to determine which MPPT configuration should be selected for applications under study. Furthermore, a new utilization of parallel MPPT configuration is introduced for operating universal input power supply (UIPS) loads to eliminate the inverter stage, thereby increasing the overall system efficiency and reliability. Finally, a systematic procedure to size the complete system is introduced and reinforced by a sizing example.
\end{abstract}

Key-Words: - Batteries, Off-Grid, Parallel MPPT, PV, Standalone and Universal Input Power Supplies.

Received: March 10, 2021. Revised: November 20, 2021. Accepted: December 23, 2021. Published: January 5, 2022.

\section{Introduction}

Off-grid standalone applications depending on photovoltaic (PV) modules as the main and sole power sources are increasing worldwide. This increase is due to many factors with the most important ones: the continuous reduction in PV system component prices, especially PV module prices, and continuous developments in PV power converter performance [1].In the literature, improvements in standalone PV systems have been addressed from many aspects in order to improve the overall system performance and open frontier for new applications [2-6]. Developments on the scale of optimizing MPPT algorithms has been addressed as shown in [7-9]. One of the addressed developments in the literature is the use of a parallel MPPT configuration instead of a series configuration [5]. In this configuration, the load is directly connected to the PV source, and a bidirectional DC-DC MPPT converter is connected in parallel with the main PV bus instead of the typically used series connection. The traditional series MPPT-based off-grid PV system is shown in Fig.1, and the parallel one is shown in Fig.2. The parallel configuration allows for direct flow of energy from the PV array directly to the load without passing through the MPPT converter during the daytime period. While, in series configuration the converter process all of the energy generated by the PV array. Therefore, losses associated within the series configuration during the daytime mode of operation are eliminated in the parallel converter, which in turn improves the overall system efficiency. However, this efficiency improvement in parallel configuration is only applicable for energy portion processed to the load during daytime. Since the amount of load daytime consumed energy varies from one standalone PV application to another, therefore, an assessment procedure is required in order to select the suitable MPPT configuration for each application. 




Fig. 1: Typical Off-grid system with Series MPPT Configuration

This assessment is important as it determines whether efficiency improvements of the parallel MPPT configuration compared to the series configuration could be achieved for a certain load profile or not.

PV standalone systems were used to feed different types of loads. These loads were categorized as AC and DC loads. One of the main types of AC loads currently used is loads that adopt universal input power supplies (UIPS) at their input power stage; these loads will be termed as UIPS loads. UIPS loads are continuously increasing, ranging from mobile phones, LED lamps, laptop chargers, battery chargers, LCD TVs, printers, scanners, network switches, routers, and desktop computers to big data servers. Currently, many residential and commercial non-motor loads are UIPS loads. The most important unique feature of these power supplies is their ability to tolerate large input supply voltage variations that could vary in the range of 90Vac up to 260Vac. Knowing that UIPS loads are equipped with an $\mathrm{AC} / \mathrm{DC}$ rectifier at their input power stage, the UIPS loads can also be operated from the DC supply. These features make them good candidates to be fed by a parallel MPPT configuration because in this configuration, the DC link voltage could be designed to match the UIPS operating voltage window. Feeding UIPS loads directly from standalone PV systems based on parallel MPPT configuration facilitates the elimination of front-end DC/AC inverters typically used with UIPS loads in typical standalone PV installations. Hence, the overall system efficiency and reliability can be improved.

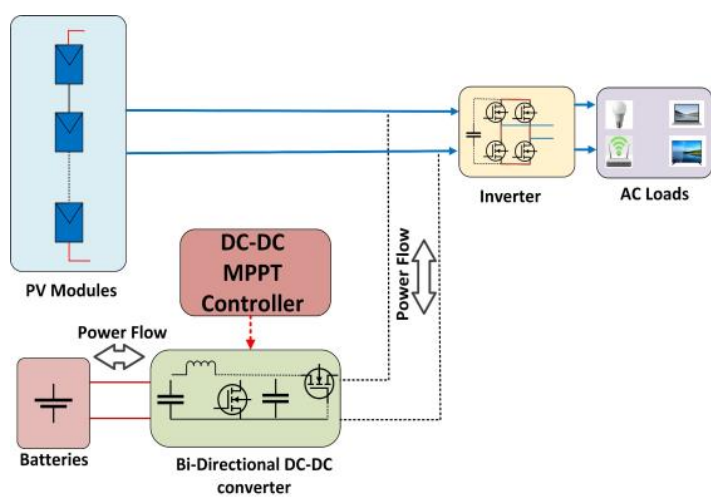

Fig. 2: Typical Off-grid system With Parallel MPPT. Configuration

In this study, an assessment framework is developed to assess the feasibility of using a parallel MPPT configuration over a series configuration based on the load daytime energy contribution. This assessment is important to provide a guide for offgrid PV system designers for selection between series and parallel MPPT configurations. In addition, a new utilisation of a parallel MPPT configuration to feed UIPS loads while eliminating the DC/AC inverter is proposed. Finally, a systematic design procedure is proposed for sizing off-grid PV systems based on a parallel configuration supplying UIPS loads.

\section{Parallel versus Series Standalone Configuration}

Fig.1 shows the traditional off-grid PV configuration for standalone off-grid PV powered AC loads with a series MPPT configuration. The main electrical components of this system consist of PV modules, series-connected MPPT DC-DC converter, battery bank, DC/AC inverter, and interconnecting cables. In this configuration, the total PV power is always processed through the series MPPT DC-DC converter. The output of the MPPT converter is connected to the batteries and the input side of the DC-AC inverter. Finally, the output of the inverter is connected to the load. This configuration is widely used in the implementation of standalone PV systems [10], [11].

The series MPPT DC-DC converter is responsible for achieving multiple functions. The first is to operate the PV string at maximum power. The second is to charge the battery bank during sun hours with excess PV power greater than the load consumed power. The third function is to safely operate the battery by limiting the battery charging when a full battery state of charge (SOC) is 
achieved and disconnects the loads when the minimum state of charge is achieved.

Typically, the rated DC voltage of the battery banks used in this configuration is 12,24 , and $48 \mathrm{~V}$, with a higher battery voltage selected for large loads to reduce conduction cable losses [12]. The DC/AC inverter is used to provide two functions: voltage stepping up in addition to DC to AC inversion.

Fig.2 shows the parallel MPPT configuration for standalone off-grid PV-powered loads. In the parallel configuration, the system components are quite similar to those used in the series configuration. However, a bidirectional DC-DC converter is used in a parallel configuration instead of a unidirectional one used in a series configuration. Because the PV array maximum power point voltage varies over the day, the main DC bus and load voltage vary accordingly. Hence, it is important to use a load front-end converter to adapt the input voltage to feed the load in a parallel MPPT configuration. The main advantage of parallel configuration over series MPPT is that it reduces the amount of losses incorporated inside the converter by allowing the direct flow of load energy from the PV array to the load during the daytime period.

\section{Parallel MPPT Modes of Operation}

The modes of operation of the parallel MPPT configuration used for supplying UIPS loads are summarized in Table1.

During mode 1, the available maximum PV power, denoted as $P_{\text {PVmax }}$, is greater than the load power, denoted as $\mathrm{P}_{\text {Load, }}$ and the battery state of charge, denoted as SOC, is less than $100 \%$, the total load power will be supplied directly from the PV string power, and the remaining PV power will be handled by the bi-directional DC-DC converter and stored in the batteries.

Table 1. Modes of Operation of Parallel MPPT Configuration

\begin{tabular}{|c|c|}
\hline $\begin{array}{l}\text { Mode } \\
\text { no. }\end{array}$ & Modes of operation \\
\hline 1 & $\mathrm{P}_{\mathrm{PV} \max }>\mathrm{P}_{\text {Load, }}$ Battery SOC less than $100 \%$. \\
\hline 2 & $\mathrm{P}_{\mathrm{PV} \max }>\mathrm{P}_{\text {Load }}$, Battery SOC equals $100 \%$. \\
\hline 3 & $\mathrm{P}_{\mathrm{PVmax}}=\mathrm{P}_{\text {Load }}$ \\
\hline 4 & $\begin{array}{l}\mathrm{P}_{\mathrm{PVmax}}<\mathrm{P}_{\text {Load }} \text {, Battery SOC greater than } \\
\text { DODmax. }\end{array}$ \\
\hline 5 & $\begin{array}{l}\mathrm{P}_{\mathrm{PVmax}}<\mathrm{P}_{\text {Load }} \text {, Battery SOC less than } \\
\text { DODmax. }\end{array}$ \\
\hline
\end{tabular}

During mode 2, the available maximum PV power is greater than the load power, and the battery state of charge SOC is equal to $100 \%$, the total load power will be supplied directly from the PV string, and the bi-directional DC-DC converter will be in idle mode as the battery cannot be overcharged. In this mode, the MPPT function is deactivated.

During mode no.3, the available maximum PV power is equal to the load power; independent of the battery SOC, the total load power will be supplied directly from the PV string power and the bidirectional DC-DC converter will be in idle mode, but this mode is rare for a long period during the day.

During mode no.4, the available maximum PV power is less than the load power, and the battery SOC is higher than the maximum allowable depth of discharge, denoted as DODmax. In this mode, a portion of the load power equal to the available maximum PV power will be supplied directly from the PV string power, and the remaining required load power is supplied by the bidirectional DC-DC converter and absorbed from the stored energy of the batteries.

During mode no.5, the available maximum PV power is less than the load power, and the battery SOC is lower than DODmax; thus, forcing the battery to discharge more power beyond its maximum DOD limit will reduce battery lifetime and system reliability, and hence either switching off some loads or the total load will be disconnected.

\section{Assessment of MPPT Configurations}

Power profiles of loads supplied by standalone PV systems can be categorized into four main types: constant, night operating loads, day time operating loads, and mixed profile loads, as indicated in Fig.3. Examples for these load profiles could be PV powered; street lighting for night operated loads as in [13], remote medical clinic for day time operated loads as in $[6,14]$. 




(a)



(b)



(c)



Fig. 3: Different load power profiles categories, (a) constant load, (b) night load, (c) daytime, (d) mixed load.

From an operational point of view, in the parallel MPPT configuration, the efficiency improvement over series one depends mainly on the amount of daytime energy consumed by the load directly from the PV array. This means that variation in the amount of daytime energy from one application to another would alter the optimum selection between parallel and series MPPT configurations. Therefore, to determine which MPPT configuration is more effective from the energy efficiency perspective, an assessment procedure for the efficiency benefits of the MPPT configuration used should be performed based on the load power profile. In this section, an assessment procedure is introduced to evaluate the parallel MPPT configuration efficiency improvements in comparison to the series one based on the load day time energy consumption.

In Fig.4, an arbitrary load and solar power profiles are shown for an arbitrary day. The load profile is divided into three portions: the first energy portion (E1) and third energy portion (E3) (pink shaded area) lay at night, while the second energy portion (E2) (yellow shaded area) lay in the daytime.
An energy flow diagram for each energy portion presented in the arbitrary load profile is shown in Fig.5 and Fig.6 for parallel and series MPPT configurations, respectively, where the energy distribution through each system component is indicated.

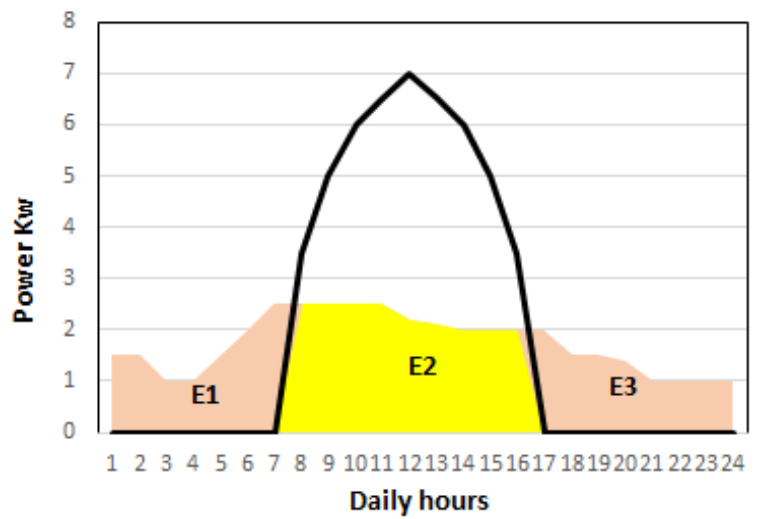

Fig. 4: Arbitrary daily load power profile (curve with pink and yellow shaded area, daily sun power profile (black curve).

From Fig.5 and Fig.6, the overall efficiency of series, denoted as $\left(\eta_{\text {ser }}\right)$, and parallel, denoted as $\left(\eta_{\text {par }}\right)$, can be calculated using (1) and (2), respectively.

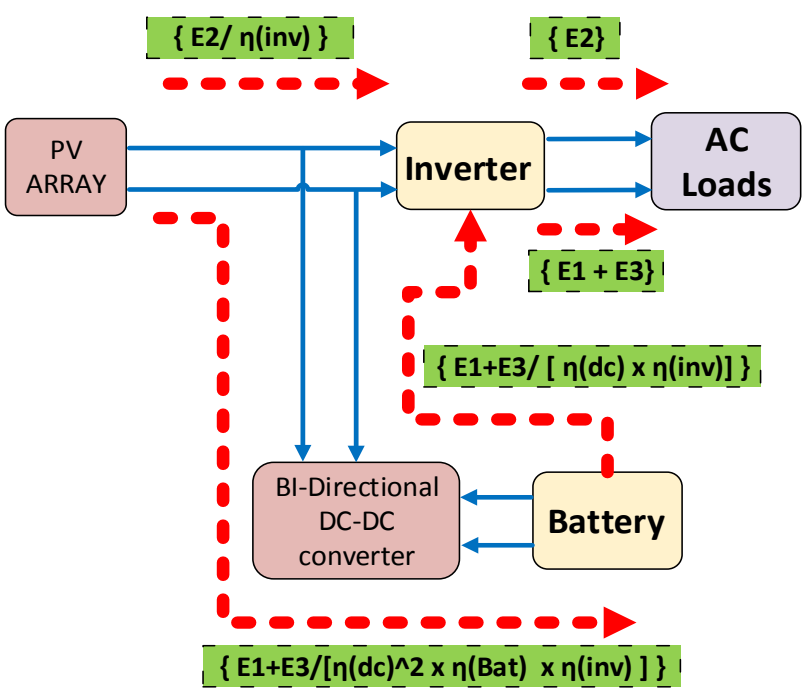

Fig. 5: Energy flow diagram of parallel MPPT configuration.

The component efficiencies used in the calculation of both efficiencies are the MPPT converter efficiency, denoted as $\eta_{\mathrm{DC}}, \mathrm{DC} / \mathrm{AC}$ inverter efficiency, denoted as $\left(\eta_{\text {inv }}\right)$, and battery efficiency $\left(\eta_{\mathrm{b}}\right)$. 


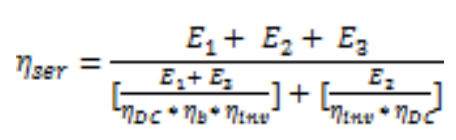

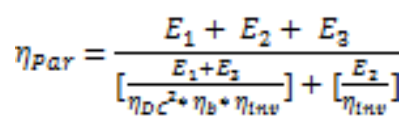

It can be seen from (1) and (2) that there are two main differences between the calculated series and parallel efficiencies. The first one is that in calculating $\eta_{\text {par }}$, the daytime energy E2 is divided only by the inverter efficiency, while the DC-DC converter efficiency is eliminated as this energy portion E2 does not pass by the DC-DC converter while transferring from the PV array to the load. The second difference, also in $\eta_{\text {par }}$, is that the nighttime energy, E1 and E3, are divided by the square of $\eta_{\text {DC. }}$. Qualitatively speaking, the effect of both differences is that as the daytime energy portion E2 increases, $\eta_{\text {par }}$ increases compared to $\eta_{\text {ser. }}$. The graphical interpretation curves of (1) and (2) are shown in Fig.7, where reasonable converters and battery efficiencies are assumed. In this curve, the efficiencies of both parallel and series configurations are plotted versus the daytime energy portion E2, where E2 is normalized with respect to the total daily energy. The Fig. shows that increasing E2 results in an increase in both the parallel and series configuration efficiencies; however, the rate of efficiency enhancement in the parallel configuration is higher than that in the series configuration.

The curves also show that beyond a certain percentage of daytime energy contribution, the parallel configuration is more efficient than the series configuration. Hence, using a parallel MPPT configuration is more efficient than using series one, provided that the daily load energy exceeded a certain percentage of the total load daily energy consumption. This percentage, as seen from the curve shown in Fig.7, lies between 55\% and 60\%. One implication of this result is that the series MPPT configuration would be the optimum selection from an energy efficiency perspective for night-only operated loads.

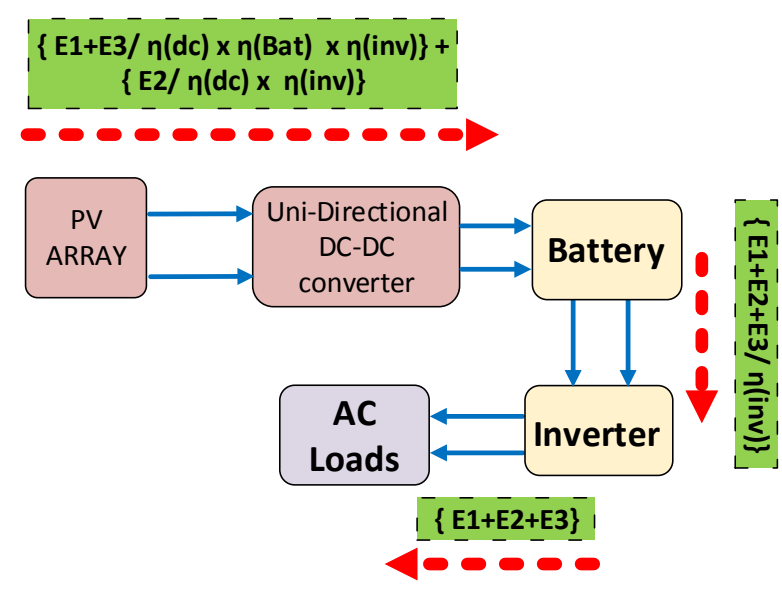

Fig. 6: Energy flow diagram of series MPPT configuration.

Simultaneously, the parallel MPPT configuration would be the optimum choice for daytime only operated loads. For loads with constant or mixed power profiles, the efficiency assessment using (1) and (2) should be performed using the actual efficiencies of each converter used to decide which MPPT configuration is more efficient. The presumed efficiencies for plotting these curves were $\left.\eta_{\mathrm{DC}}=0.95, \eta_{\text {inv }}=0.95, \eta_{\mathrm{b}}=0.85\right)$.

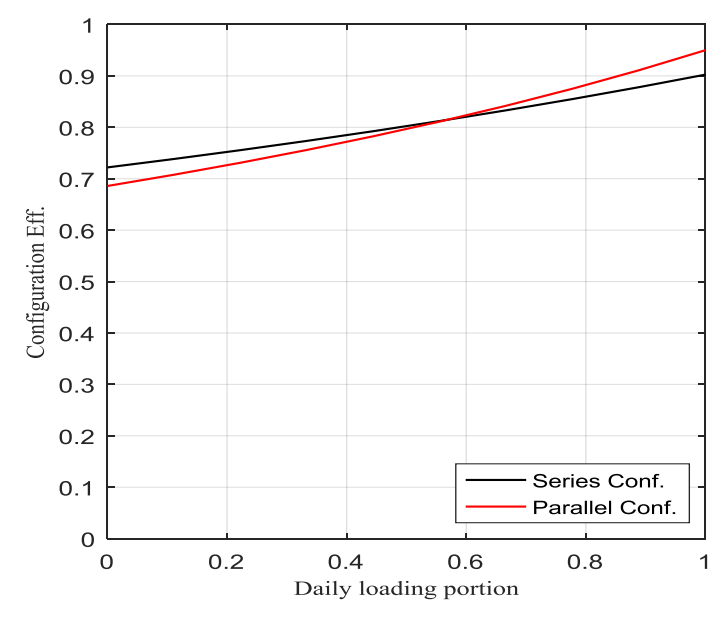

Fig. 7: Parallel and series configuration efficiencies versus daily loading portion.

Although the DC -DC converter efficiencies vary from one converter topology to another, in this analysis, the efficiencies of both unidirectional converters, used in series, and bidirectional converters used in parallel, were assumed to be the same. This was done to neutralize the comparison between series and parallel configurations from efficiency differences due to converter topology and concentrate on the load curve effects on the overall system efficiency. However, the actual efficiencies 
of the selected converter can be considered in the configuration efficiency assessment framework presented by applying the actual efficiency value for each configuration.

\section{New Utilization of Parallel MPPT Configuration}

In this section, a new utilization of the parallel MPPT configuration for supplying UIPS loads is introduced, as shown in Fig.8. This proposal is driven by four main factors, the first factor is the wide spreading of UIPS loads with their superior feature of accepting wide AC as well as DC supply voltage variations. The second factor is the continuous increase in the market share of PV powered off-grid applications, which is a direct result of the continuous price reduction in PV system costs. The third factor is the capability of the parallel MPPT configuration to enhance the overall system efficiency compared to the series configuration for certain applications with high day time energy contributions. The fourth factor is the capability to eliminate one of the main system components encountered in the design of off-grid PV systems feeding AC loads, which is the AC/DC inverter, which in turn has a positive impact on the overall system cost, system efficiency, and reliability.

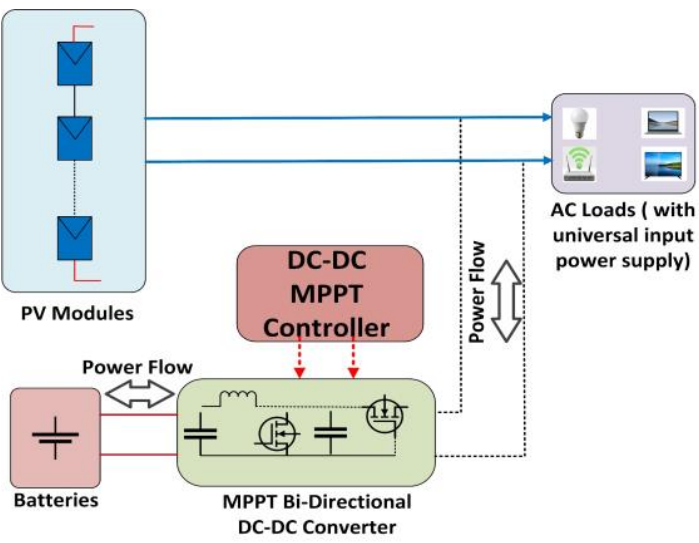

Fig. 8: Proposed System Configuration

The advantages of reduced overall system costs and enhanced system efficiency and reliability would pave the way for the development of MPPT bidirectional DC/DC converters dedicated to standalone PV systems on a commercial scale.

This new utilization imposes a new design constraint while sizing the PV array. This constraint is that the variation of the PV string voltage window during day operating hours should fall within the
UIPS load operating voltage window. This design constraint ensures the proper operation of the load. In the next section, this constraint is considered while sizing a full standalone system feeding UIPS loads.

\section{System Sizing}

In this section, the sizing of standalone PV systems for the proposed parallel MPPT configuration feeding UIPS loads is introduced. Similar to any standalone PV system, in the proposed configuration, the system components to be sized are as follows:

1) The PV module data includes the module maximum power, Pmax, number of modules per string, number of parallel strings, and module voltage ratings (the maximum power point voltage, $\mathrm{V}_{\mathrm{mpp}}$, and open-circuit voltage $\mathrm{Voc}$ ).

2) Battery bank ratings include battery chemistry type, battery nominal voltage, and battery Ampere-Hour Capacity (AH).

3) The ratings of the DC/DC MPPT charge controller.

4) Cable sizing per each stage including cable cross-sectional area and lengths.

The required design input data to determine and size the above-mentioned system components are as follows.

1) Estimated load power profile versus time for the worst design month. This month has the lowest daily sun-peak hours for constant load power profiles. However, with varying load profiles, this month should be the month with the highest ratio of daily energy consumption divided by its associated sun peak hours.

2) Required days of autonomy to account for cloudy and sunless days, Nauto.

In the proposed configuration, a modified design methodology is used to size and select the complete system components listed above. This modified methodology guarantees matching between the sized PV string Vmpp window and the allowed UIPS voltage window. This matching between both voltage windows is mandatory to allow for proper load operation.

\subsection{PV Array Sizing}

In this section, the PV array sizing parameters are determined, which are the total PV array power, 
denoted as $\mathrm{Pt}$, number of series modules per string, denoted as Ns , and number of parallel strings, denoted as $\mathrm{Np}$.

The first sizing parameter which is the total PV array power, $\mathrm{Pt}$, is determined based on three factors, as shown in (3). The first factor is the reflected load power, denoted as $\mathrm{K}_{\mathrm{EH}}$. where $K_{E H}$ is calculated by dividing the daily load energy consumption ( $\mathrm{E}_{\text {dailv }}$ ) by the corresponding daily sun peak hours (SPH), as shown in (4). The second factor is the overall efficiency factor $\eta_{*}$, which includes module temperature losses, soiling losses, cabling losses, DC-DC converter losses, and battery cyclic losses. The last factor is the autonomy oversizing factor $\left(\mathrm{K}_{\Theta}\right)$, which is used to account for the extra charging energy required to charge batteries after battery deep discharging during cloudy days. In calculating Pt, sizing based on the maximum value of $\mathrm{K}_{\mathrm{EH}}$ (i.e. $\left(\mathrm{K}_{\mathrm{EH}}\right)_{\max }$ ) ensures the capability of the PV array to supply load energy requirements during the worst day.

$$
\begin{gathered}
P_{\mathrm{t}}=\frac{\left(K_{E H}\right)_{\max } \times K_{a}}{\eta_{t}} \\
K_{E H}=\left(\frac{E_{\text {daily }}}{S P H_{\text {daily }}}\right)
\end{gathered}
$$

The next step in sizing the PV array is to determine the number of series modules per string, denoted as Ns .During the day, the PV string output voltage, denoted as $\mathrm{V}_{\text {string, should be within the }}$ allowed voltage window dictated by the UIPS load. Because $V_{\text {string }}$ equals the module voltage, denoted as $\mathrm{V}_{\bmod }$, multiplied by Ns, as shown in (5), selecting Ns will depend on the UIPS voltage window limits and the output voltage per module.

$$
V_{\text {string }}=V_{\text {mod }} * N_{g}
$$

The module output voltage $\mathrm{V}_{\text {mod }}$ varies depending on many factors. The first factor is the module technology used, whether it is crystalline silicon, C$\mathrm{Si}$, or thin-film, and the second factor is the number of cells per module. The third factor is the environmental operating conditions and, more specifically, the module temperature. The last factor affecting $\mathrm{V}_{\text {mod }}$ was the electrical loading condition. The first three factors determine the I/ $\mathrm{V}$ curve of the PV module, while the latter determines the point at which the PV module is operating. It is obvious that the module output voltage that is considered in the calculations, while selecting $\mathrm{Ns}$, is the maximum

power point voltage, denoted as $V_{m p p}$, as operating at this voltage ensures maximising the output power of the PV array. It should be noted that module

$V_{m p p}$ will also vary during the daytime because of module temperature and irradiance variations. The benefit of utilizing UIPS loads which have a unique feature of accepting a wide range of input supply

voltages that are capable of covering $V_{m p p}$ voltage

variations during daytime. To fit the $V_{m p p}$ voltage variation into the UIPS voltage window, Ns should be appropriately selected. The optimum Ns is bounded by Nsmax and Nsmin, as shown in (6). Where Nsmax and Nsmin are the maximum and the minimum allowed number of series-connected modules per string that ensure fitting of the $V_{m p p}$ in to the UIPS voltage window.

$N_{S \min }<N_{S}<N_{S \max }$

Formulas for determining $\mathrm{N}_{\text {smin }}$ and $\mathrm{N}_{\text {smax }}$ are shown in (7) and (8), respectively. A new DC bus voltage window is defined based on the UIPS input voltage window to account for $\mathrm{V}_{\mathrm{mpp}}$ variation during daytime and to allow for some voltage safety margin. The two limits defining this new voltage window are denoted as $\mathrm{V}_{\text {Smin }}$ and $\mathrm{V}_{\text {Smax }}$, representing the lower and upper voltage window limits, respectively.

$V_{\text {Smin }}<N_{S \min } * V_{\text {mpp_sTC }}$

$N_{S \max } * V_{\text {mpp_sTC }}<V_{S \max }$

This new window is related to the UIPS input voltage window by a voltage variation factor, denoted as $\mathrm{K}_{\mathrm{vf}}$, which accounts for the deviation of the operating $\mathrm{V}_{\mathrm{mpp}}$ from its nominal STC value,

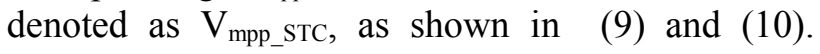
Moreover, a $10 \%$ margin is considered to leave a suitable safety margin over the UIPS window limits. The voltage variation factor $K_{v f}$ depends on the 
range of variation of the module temperature and voltage temperature coefficient of the module used.

$$
\begin{aligned}
& V_{\text {Smin }}=V_{\text {UIPS_min }} * 1.1 * K_{V f} \\
& V_{\text {Smax }}=\frac{V_{\text {UIPS max }}}{1.1^{*} K_{\text {VIf }}}
\end{aligned}
$$

From (7) and (8), the allowed range for $\mathbf{N}_{S}$ is determined.

The next step in sizing the PV array is to determine the number of parallel PV strings in the array, denoted as $\mathrm{Np}$. For applications with relatively high-power requirements, paralleling of PV strings is needed. To check whether parallel PV strings are needed, the minimum required power per PV module, denoted as $\mathrm{P}_{\text {Mod_min, should be }}$ calculated. An iterative procedure was used to determine $\mathrm{P}_{\text {Mod_min }}$ using (11).

$$
\frac{P_{t} * V_{\text {mpp_STC }}}{N_{P} V_{\text {Smax }}}<P_{\text {Mod_min }}
$$

For the first iteration, the number of parallel strings, $\mathrm{Np}$, is set equal to one, and then $\mathrm{P}_{\text {Mod_min }}$ is calculated. If PV modules with this power do not exist in the market, paralleling of PV strings will be required. In this case, $\mathrm{Np}$ is incremented by one and $\mathrm{P}_{\text {Mod_min }}$ is recalculated until $\mathrm{P}_{\text {Mod_min }}$ is achieved, which is less than or equal to the market available PV module power. Then, the number of parallel strings $\mathrm{Np}$ is set equal to the last increment iteration. After setting the value of $\mathrm{Np}, \mathrm{P}_{\bmod }$ will be selected from market-available modules such that its value is greater than or equal to $\mathrm{P}_{\text {Mod_min. Finally, Ns was }}$ calculated using (12).

$$
N_{S}=\frac{P}{N_{p} * P_{\text {mod }}}
$$

\subsection{Battery Sizing}

The first design parameter to consider in battery bank sizing is deciding the battery chemistry to be used. The battery chemistry selected in any application is based on the battery performance parameters of interest required by the application. Generally speaking, the battery's main performance parameters are battery specific energy and power densities, internal discharge rate, memory effect behavior, number of charge/discharge cycles of the battery, and maximum allowed depth of discharge,

denoted as $D O D_{\max }$. For standalone $\mathrm{PV}$ applications, the last two performance parameters are the most important parameters to be considered while selecting the battery chemistry used. Lead acid batteries are the most adopted battery chemistry in many off-grid PV installations [15], as they are considered to be the cheapest rechargeable battery technology [16]. However, it is expected that lithium-ion batteries will replace lead-acid batteries in the near future because of their continuous price reduction [17] and, of course, their superior performance over lead acid.

After selecting the battery chemistry, the second parameter to consider is the battery energy capacity

$\mathrm{E}_{\mathrm{b}}$ which, which is determined based on the maximum daily load energy, denoted as $E_{\text {daily_max }}$. Because, in the proposed parallel configuration, the battery is positioned after the DC to DC converter,

the converter efficiency along with the $D O D_{\max }$,

and days of autonomy, denoted as $N_{\text {auto }}$, should be considered while determining the battery capacity, as shown in (13).

$$
E_{b}=\frac{E_{\text {dailygmax }} \times N_{\text {auto }}}{D O D_{\max } \times \eta_{d e-d e}}
$$

Next to the calculation of the battery bank capacity, the battery bank voltage is selected. In the proposed configuration, the converter used should be bidirectional, in contrast to the unidirectional converter found in the traditional configuration. The battery bank voltage should be selected to be suitable for all operation modes of the selected bidirectional DC-DC converter. In a series MPPT configuration, it is common to select a battery bank voltage of 12,24 or $48 \mathrm{~V}$. The same voltage levels can be selected in the parallel MPPT configuration or even higher, depending on the bidirectional DCDC converter voltage ratings.

\subsection{Converter Sizing}

The proposed configuration utilizes a parallel bidirectional DC-DC converter instead of a series unidirectional converter used in traditional stand- 
alone PV system configurations. Although the commercial availability of the bidirectional DC-DC converter is relatively lower than that of the unidirectional converter, its market share is estimated to increase in the near future, mainly because of continuous development in the emobility and micro-grid sectors. Some of the commercially available bidirectional DC-DC converters can be found in the referenced datasheets [18], [19].

The main sizing specifications of the bidirectional DC-DC converter are the power rating, low voltage, and high-voltage side voltage window limits. The converter power rating is determined based on the maximum of the charging, denoted as $\mathrm{P}_{\mathrm{Ch} \_ \text {max }}$, and the discharging power of the converter, denoted as $P_{\text {Load_max. }}$ The maximum charging and discharging powers depend on the load power profile versus time and PV array power. It is recommended to account for a $10 \%$ oversizing safety factor in calculating the converter maximum power, as shown in (14).

$$
\mathrm{P}_{\text {Conw_max }}=1.1 * \max \left\{\mathrm{P}_{\text {Ch_max }_{\text {max }}} \mathrm{P}_{\text {Load }_{-} \max }\right\}
$$

The converter low-voltage side was selected as the battery side, and its voltage window limits were $\mathrm{V}_{\text {bmax }}$ and $\mathrm{V}_{\text {bmin. }}$. Where $\mathrm{V}_{\text {bmax }}$ is the maximum attainable battery voltage under fully charged conditions, and $\mathrm{V}_{\mathrm{bmin}}$ is the minimum operating battery voltage at the minimum allowed state of charge. These battery voltage limits are determined from the battery datasheet; however, it is common to be $15 \%-20 \%$ away from the nominal battery voltage values. The high-voltage side of the converter is connected to the main DC bus; hence, its voltage window should be equal to or wider than that of the UIPS voltage window.

\subsection{Cable Sizing}

Cables represent a main component in the off-grid PV system and share a considerable percentage of the total system losses. Designers typically consider that their losses share between $2 \%$ and $5 \%$ relative to the system peak power [20], [21]. Transferring the same amount of power over a higher voltage level decreases the operating current, thereby reducing losses and allowing for lower cable crosssectional area, csa, usage. Typical off-grid PV systems operate with standardized DC bus voltages of 12,24 , or $48 \mathrm{~V}$. The selection of a higher operating voltage is usually recommended for larger load powers to reduce operating current which reduces cable losses, assuming constant current density for cable sizing. In the proposed configuration, power is transferred to the load through a voltage level that lies in the range of 130$320 \mathrm{~V}$. This range is greater than the typical DC bus voltage used for traditional off-grid PV systems; hence, the cable transmission efficiency in the proposed configuration is enhanced. In addition, this feature can be used to use cables with a lower crosssectional area which decreases the overall system cost.

The proposed configuration comprises three main cables for which the csa and length should be determined. The first cable is the main DC bus cable connecting the $\mathrm{PV}$ array to the bidirectional converter, the second one is the load connection cable to the main DC bus, and the third one is the battery connection cable to the bidirectional converter. The length of the cable is determined based on the relative physical allocation of the system components. Component allocation that allows shorter cable lengths is preferable for reducing the voltage drop and power losses.

From the cable manufacturer catalogues, the cable csa is selected based on the calculated maximum cable current and maximum allowed resistance per unit length that satisfies the maximum allowed voltage drop. The calculation of the maximum current and maximum allowed resistance per unit length $(\mathrm{km})$ is shown in (15) and (16), respectively.

$$
\begin{gathered}
I_{\max }=\frac{P_{\max }}{V_{\operatorname{smin}}} \\
R_{\max }=\frac{V_{d r o p}}{I_{\max } * \text { Cable length }}
\end{gathered}
$$

\subsection{Case Study}

In this section, the sizing of the complete parallel MPPT off-grid PV system feeding the UIPS load is determined following the steps illustrated in the sizing section. The sizing of the PV array, batteries, DC-DC converter, and cables will be determined.

For a given off-grid area utilizing UIPS loads, the daily energy consumption for a standalone application on the worst design day was $12 \mathrm{kWh}$, and the corresponding SPH was 4 . The days of the

autonomy factor $\mathrm{K}_{\text {auto }}$ are assumed to be 1.25 .

From this value of $\mathbf{K}_{\text {auto }}$ the batteries will take 12 
days to recharge the autonomy battery capacity after a full 3 days autonomy period. The overall efficiency was assumed to be 0.75 . Therefore, substituting in (3), the required PV power at STC

\section{$\left(\mathrm{P}_{t}\right)$ equals the $5 \mathrm{~kW}$ peak.}

The UIPS allowed the DC supply window to typically range from 130 to $320 \mathrm{VDC}$. The voltage variation factor, Kvf, was assumed to be 1.2. By substituting in (7) and (8), Vsmin and Vsmax are $172 \mathrm{~V}$ and $242 \mathrm{~V}$, respectively. The selected number of PV modules per string, Ns, should produce a voltage that lies within this range (from 172 to 242 V) under different operating conditions. From the PV module type selected, Vmpp_STC is determined and substituted in (11) to obtain Pmod_min while assuming $\mathrm{NP}=1$. Owing to its high commercial availability and hence relatively lower price per watt, the 60 cell C-Si module will be selected. Sixty cell PV module has a Vmpp STC that varies from 30 to $35 \mathrm{~V}$ depending on the module design; in calculations, $33 \mathrm{~V}$ will be used. From the substitution in (11), $\mathrm{P}_{\min }$ equals $682 \mathrm{~W}$. Because $\mathrm{P}_{\min }$ is higher than the maximum of any available commercial 60 cell module, parallel strings are required. By incrementing $\mathrm{Np}$ to two, $\mathrm{P}_{\min }$ equals $341 \mathrm{~W}$. This value of $\mathrm{P}_{\min }$ is commercially available in 60 cell modules range. From commercially available modules, JAM60s20-365/MR [22] was selected. This module is rated at $365 \mathrm{~W}$ and Vmpp_STC equals 33.96V. The number of modules per string, Ns, is then calculated using (12) which equals seven modules per string. Therefore, the PV array consists of two parallel strings with seven series modules per string with a total power of 5110 $\mathrm{W}$ under STC conditions.

To size the battery, first, the battery chemistry will be selected. Owing to its wide market availability and high number of charge/discharge cycles, deep-cycle lead acid chemistry will be

selected. $\mathrm{N}_{\text {auto }}$ is assumed to be 3 days, $\eta_{\mathrm{dc}-\mathrm{dc}}$ is assumed to be 0.95 . $\mathrm{DOD}_{\max }$ was chosen to be $80 \%$. Using (13), the required battery capacity was 48 $\mathrm{kWh}$. The operating battery voltage was selected to be $48 \mathrm{~V}$. Hence, the AH capacity of the battery was $1000 \mathrm{AH}$.

The next step is to size the bi-directional DCDC converter. From the load power profile and size of the PV array, the maximum power of both is equal to $6.3 \mathrm{Kw}$. Therefore, from (3), the power rating of the converter is $7 \mathrm{~kW}$. The voltage ratings of the converter battery side are rated the same as the battery nominal voltage at $48 \mathrm{~V}$. However, the converter should be capable of operating in a window of $\pm 20 \%$ around this voltage to allow for battery voltage variations during charging and discharging. As stated earlier in the design section, the voltage ratings of the converter DC side connected to the main DC bus are rated based on UIPS voltage window limits which are 130 and $320 \mathrm{~V}$ DC. Therefore, the Bidirectional DC-DC converter ratings are as follows: power rating of 7 $\mathrm{kW}$, battery side voltage of $48 \mathrm{~V}( \pm 20 \%), 240 \mathrm{~V}( \pm$ $50 \%)$.

After sizing the converter, the cable sizes were determined. Typically, the cable lengths are dictated by the physical orientation of the system components relative to each other. This, in turn, is dependent on the locations of off-grid sites ready for system installation. In the case under study, only the main DC bus cable is sized, and the other two system cables can be sized using the same procedure. To determine the csa of this cable, first, the maximum current flowing through the circuit should be determined as shown in (15).Based on this calculation, the maximum current of the main DC bus is approximately $39 \mathrm{~A}$. This current is calculated based on the UIPS minimum voltage window limit which is equal to $130 \mathrm{~V} \mathrm{DC}$ at the maximum PV power. From one of the PV cable manufacturer's catalogue [23], $2.5 \mathrm{~mm} 2$ or $4 \mathrm{~mm} 2$ csa would be sufficient to handle this amount of current. However, assuming that the cable length is to $40 \mathrm{~m}$ (two ways), this csa would produce a high voltage drop and hence high power losses which is equal to $10 \%$ approximately at the lowest allowed supply voltage condition. By setting the allowed voltage drop to $3 \%$, using (16), the maximum acceptable resistance per $\mathrm{km}$ is equals to $2.5 \Omega / \mathrm{km}$. This resistance could be achieved using a $10 \mathrm{~mm} 2$ cable. In this step, the sizing of the off-grid PV system supplying the UIPS based on parallel MPPT is performed.

\section{Discussion}

The system efficiency analysis presented in section 4 showed that the efficiency improvements in parallel MPPT configuration over series one is not justified for all applications. It was shown that the efficiency improvements depends on the amount of load daytime energy contribution with respect to the total daily energy consumption. So, for standalone applications with high daytime energy contributions it is advised to use the parallel MPPT configuration, 
this amount is roughly around $50 \%$. The accurate percentage could be calculated as shown in section 4.

The nature of the input interfacing power converter of the UIPS loads, such as LED [24], allows for two operating features which was well utilized in this paper to match the operating behavior of parallel MPPT configuration and directly connect UIPS load to the main DC bus. These two features are the wide operating input voltage window and the capability to be operated from DC source. These two features allows for directly suppling the UIPS loads from the DC bus of the parallel MPPT configuration, provided that well sizing of PV string is done, as shown in section 6.1. Suppling UIPS load from the main DC bus directly, allows the elimination of the $\mathrm{DC} / \mathrm{AC}$ inverter stage which is typically used in standalone PV systems feeding the UIPS loads, which enhances overall system efficiency and reliability.

\section{Conclusion}

In this paper, an assessment procedure to assess efficiency improvements of parallel MPPT configuration over series one based on the load power profile is introduced. The assessment procedure showed that if the daytime load energy consumption is lower than $50 \%$ of the total load daily energy, the series MPPT configuration will be preferred over parallel MPPT from an energy efficiency perspective. Moreover, a new utilization of the parallel MPPT configuration is introduced to supply the UIPS load. This utilization eliminates the $\mathrm{DC} / \mathrm{AC}$ inverter stage which increases the overall system efficiency and reliability, however this elimination is valid only for UIPS loads. Finally, a detailed design procedure for a parallel MPPT feeding UIPS load is presented, along with a detailed case study.

The future work for this research is to implement hardware setup for a small prototype with UIPS loads.

\section{References:}

[1] G. Kavlak, J. McNerney, and J. E. Trancik, "Evaluating the causes of cost reduction in photovoltaic modules," Energy Policy, vol. 123, pp. 700-710, 2018, doi: 10.1016/j.enpol.2018.08.015.

[2] L. A. Lamont and L. El Chaar, "Enhancement of a stand-alone photovoltaic system's performance: Reduction of soft and hard shading," Renew.
Energy, vol. 36, no. 4, pp. 1306-1310, 2011, doi: 10.1016/j.renene.2010.09.018.

[3] M. Das and V. Agarwal, "Novel HighPerformance Stand-Alone Solar PV System With High-Gain High-Efficiency DC-DC Converter Power Stages," IEEE Trans. Ind. Appl., vol. 51, no. 6, pp. 4718-4728, 2015, doi: 10.1109/TIA.2015.2454488.

[4] L. A. Lamont and L. El Chaar, "Enhancement of a stand-alone photovoltaic system's performance: Reduction of soft and hard shading," Renew. Energy, vol. 36, no. 4, pp. 1306-1310, 2011, doi: 10.1016/j.renene.2010.09.018.

[5] R. Gules, J. D. P. Pacheco, H. L. Hey, and J. Imhoff, "A maximum power point tracking system with parallel connection for PV standalone applications," IEEE Trans. Ind. Electron., vol. 55, no. 7, pp. 2674-2683, 2008, doi: 10.1109/TIE.2008.924033.

[6] Hanaa M. Farghally, Ninet M. Ahmed, Abd ElShafy A. Nafeh, Faten H. Fahmy, Amal A. Hassan, Emaad A. Sweelem, Water from Air Production System based on Solar Energy in Egypt, International Journal of Mechanics, Volume 14, 2020, pp. 215-220.

[7] M. M. Eshak, M. A. Khafagy, P. Makeen and S. O. Abdellatif, "Optimizing the performance of a stand-alone PV system under non-uniform irradiance using Gray-Wolf and hybrid neural network AI-MPPT algorithms," 2020 2nd Novel Intelligent and Leading Emerging Sciences Conference (NILES), 2020, pp. 600-605, doi: 10.1109/NILES50944.2020.9257965.

[8] Windarko, N.A.; Nizar Habibi, M.; Sumantri, B.; Prasetyono, E.; Efendi, M.Z.; Taufik. A New MPPT Algorithm for Photovoltaic Power Generation under Uniform and Partial Shading Conditions. Energies 2021, 14, 483. https://doi.org/10.3390/en14020483.

[9] Vipin Kumar, Sandip Ghosh, N.K. Swami Naidu, Shyam Kamal, R.K. Saket, S.K. Nagar,Load voltage-based MPPT technique for standalone PV systems using adaptive step,

International Journal of Electrical Power \& Energy Systems,

Volume 128,2021,106732,ISSN 0142-0615,

[10] H. El-Houari et al., "Design, simulation, and economic optimization of an off-grid photovoltaic system for rural electrification," Energies, vol. 12, no. 24, 2019, doi: 10.3390/en12244735.

[11] J. Song and Y. Choi, "Design of photovoltaic systems to power aerators for natural purification of acid mine drainage," Renew. Energy, vol. 83, pp. 759-766, 2015, doi: 10.1016/j.renene.2015.05.014.

[12] N. D. Nordin and H. Abdul Rahman, "A novel optimization method for designing standalone 
photovoltaic system," Renew. Energy, vol. 89, pp. 706-715, 2016, doi: 10.1016/j.renene.2015.12.001.

[13] E. I. Archibong, S. Ozuomba and E. Ekott, "Internet of Things (IoT)-based, Solar Powered Street Light System with Anti-vandalisation Mechanism," 2020 International Conference in Mathematics, Computer Engineering and Computer Science (ICMCECS), 2020, pp. 1-6, doi: 10.1109/ICMCECS47690.2020.240867.

[14] Hanaa M. Farghally, Ninet M. Ahmed, Abd ElShafy A. Nafeh, Faten H. Fahmy, Amal A. Hassan, Emaad A. Sweelem, Water from Air Production System based on Solar Energy in Egypt, International Journal of Mechanics, Volume 14, 2020, pp. 215-220.

[15] S. Paul Ayeng'o, T. Schirmer, K. P. Kairies, H. Axelsen, and D. Uwe Sauer, "Comparison of off-grid power supply systems using lead-acid and lithium-ion batteries," Sol. Energy, vol. 162, no. December 2017, pp. 140-152, 2018, doi: 10.1016/j.solener.2017.12.049.

[16] Pavlov, D. (2011). In Lead-acid batteries: science and

technology: a handbook of lead-acid battery technology and its influence on the product. Essay, Elsevier Science Ltd.

[17] Y. Zhao et al., "A Review on Battery Market Trends, Second-Life Reuse, and Recycling," Sustain. Chem., vol. 2, no. 1, pp. 167-205, 2021, doi: 10.3390/suschem2010011.

[18] Epic Power bidirectional DC/DC converters brochure, https://epicpower.es/wpcontent/uploads/2019/05/EPC_ENG_2019_broc hure_.pdf

[19] TDK-Lambda Corporation, product information, https://eu.mouser.com/pdfdocs/TDKLambdaAp plicationNote.PDf.

[20] S. Jogunuri, R. Kumar, and D. Kumar, "Sizing an off-grid photovoltaic system (A case study)," 2017 Int. Conf. Energy, Commun. Data Anal. Soft Comput. ICECDS 2017, pp. 2618-2622, 2018, doi: 10.1109/ICECDS.2017.8389927.

[21] W. Ali, H. Farooq, A. U. Rehman, Q. Awais, M. Jamil, and A. Noman, "Design considerations of stand-alone solar photovoltaic systems," 2018 Int. Conf. Comput. Electron. Electr. Eng. ICE Cube 2018, no. November, pp. 1-6, 2019, doi: 10.1109/ICECUBE.2018.8610970.

[22] https://www.jasolar.com.cn/uploadfile/2020/0619 /20200619041705631.pdf

[23]https://www.smsystems.co.in/POLYCABSOLAR-Cable.pdf

[24] Deepak Agrawal, Rajneesh Kumar Karn, Deepak Verma, Rakeshwri Agrawal, DC-DC Converter Topologies for LED Driver Circuit: A Review, International Journal of Circuits,
Systems and Signal Processing, Volume 14, 2020, pp. 542-547.

\section{Creative Commons Attribution License 4.0 (Attribution 4.0 International, CC BY 4.0)}

This article is published under the terms of the Creative Commons Attribution License 4.0 https://creativecommons.org/licenses/by/4.0/deed.en US 